WSRC-TR-2003-00198

\title{
PERFORMANCE EVALUATION OF O-RING SEALS IN THE SAFKEG 3940A PACKAGE IN KAMS (U)
}

\author{
T. Eric Skidmore \\ Savannah River Technology Center \\ Strategic Materials Technology Department \\ Materials Technology Section
}

May 2003

Patent Status

This internal management report is being transmitted

without DOE patent clearance, and no further

dissemination or publication shall be made of the report

without prior approval of the DOE-SR patent counsel.

\section{Westinghouse Savannah River Company Savannah River Site Aiken, SC 29808}

This document was prepared in connection with work done under Contract No. DE-AC09-96SR18500 with the U. S. Department of Energy 
This document was prepared in conjunction with work accomplished under Contract No. DE-AC09-96SR18500 with the U. S. Department of Energy.

\section{DISCLAIMER}

This report was prepared as an account of work sponsored by an agency of the United States Government. Neither the United States Government nor any agency thereof, nor any of their employees, makes any warranty, express or implied, or assumes any legal liability or responsibility for the accuracy, completeness, or usefulness of any information, apparatus, product or process disclosed, or represents that its use would not infringe privately owned rights. Reference herein to any specific commercial product, process or service by trade name, trademark, manufacturer, or otherwise does not necessarily constitute or imply its endorsement, recommendation, or favoring by the United States Government or any agency thereof. The views and opinions of authors expressed herein do not necessarily state or reflect those of the United States Government or any agency thereof.

This report has been reproduced directly from the best available copy.

Available for sale to the public, in paper, from: U.S. Department of Commerce, National Technical Information Service, 5285 Port Royal Road, Springfield, VA 22161, phone: (800) 553-6847, fax: (703) 605-6900

email: orders@ntis.fedworld.gov

online ordering: http://www.ntis.gov/help/index.asp

Available electronically at http://www.osti.gov/bridge

Available for a processing fee to U.S. Department of Energy and its contractors, in paper, from: U.S. Department of Energy, Office of Scientific and Technical Information, P.O. Box 62, Oak Ridge, TN 37831-0062,

phone: (865)576-8401,

fax: (865)576-5728

email: $\underline{\text { reports@ adonis.osti.gov }}$ 


\section{TABLE OF CONTENTS}

Page

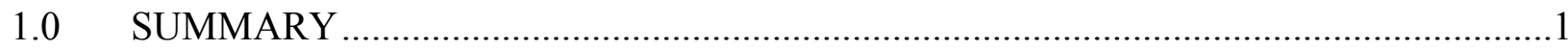

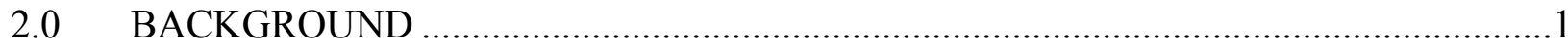

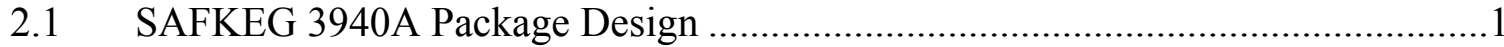

2.2 O-Ring Material Specification ......................................................................4

2.3 Service Conditions ................................................................................. 4

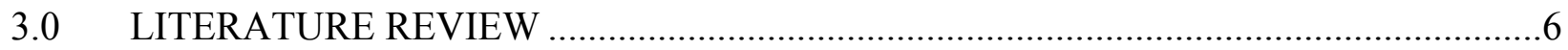

3.1 EPDM Chemistry, Formulation and General Properties ...................................6

3.2 General Aging of Elastomers .....................................................................

3.3 Thermal Aging of EPDM Elastomers......................................................... 9

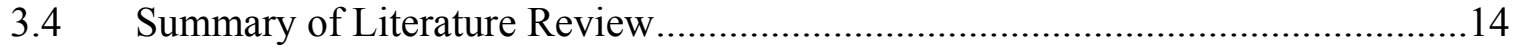

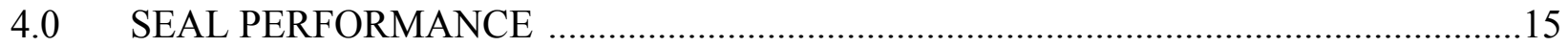

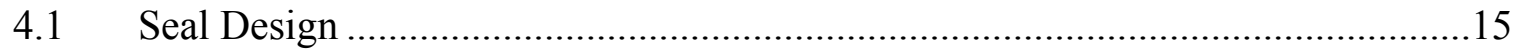

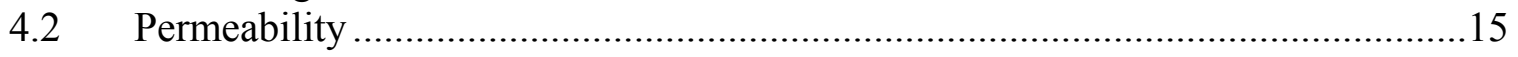

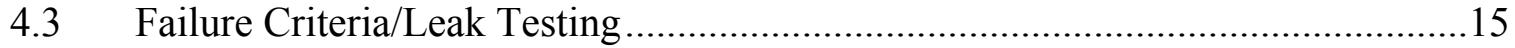

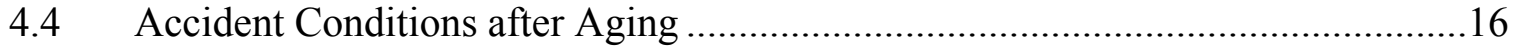

4.5 Baseline Characterization ........................................................................ 16

5.0 CONCLUSIONS AND RECOMMENDATIONS .................................................. 17

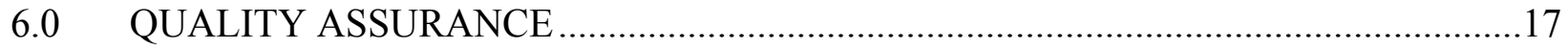

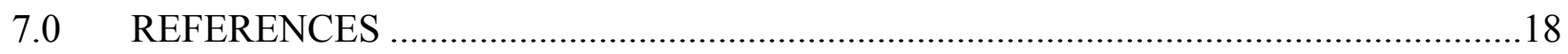




\section{LIST OF TABLES}

Table 1. Nominal Properties of Rainier Rubber O-Ring Compound\# R0629-60.......................5

Table 2. $\quad$ Bounding Conditions for SAFKEG 3940A and Model 9975 Packages ......................5 


\section{LIST OF FIGURES}

Figure 1. Overall Diagram of the SAFKEG 3940A Package Assembly...............................2

Figure 2. Inner and Outer Containment Vessel Design........................................................3

Figure 3. Chemical Structure of EPR and EPDM Elastomers ..........................................6

Figure 4. Ultimate Tensile Elongation vs. Aging Time for EPDM ...................................12

Figure 5. Normalized Compression Stress Relaxation vs. Aging Time for EPDM ................12

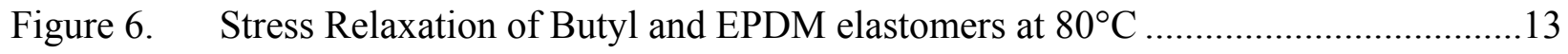




\section{LIST OF ACRONYMS, TRADENAMES, AND ABBREVIATIONS}

$\begin{array}{ll}\text { ASTM } & \text { American Society for Testing and Materials } \\ \text { CSR } & \text { compression stress-relaxation } \\ \text { DBA } & \text { design basis accident } \\ \text { DED } & \text { dose to equivalent damage } \\ \text { DLO } & \text { diffusion-limited oxidation } \\ \text { EPDM } & \text { ethylene-propylene diene monomer } \\ \text { EPR } & \text { ethylene-propylene rubber } \\ \text { FKM } & \text { ASTM designation for fluorocarbon rubber } \\ \text { Gray } & \text { International unit of radiation absorbed dose, 1 Gray }(\mathrm{Gy})=100 \mathrm{rad} \\ \text { ICV } & \text { Inner Containment Vessel } \\ \text { IEEE } & \text { Institution for Electrical and Electronic Engineers } \\ \text { HAC } & \text { Hypothetical Accident Conditions } \\ \text { KAMS } & \text { K-Area Materials Storage } \\ \text { LANL } & \text { Los Alamos National Laboratory } \\ \text { MNOP } & \text { Maximum Normal Operating Pressure } \\ \text { NCT } & \text { Normal Conditions of Transport } \\ \text { OCV } & \text { Outer Containment Vessel } \\ \text { phr } & \text { parts per hundred rubber (elastomer compounding units) } \\ \text { RAM } & \text { Radioactive Material } \\ \text { rad } & \text { radiation absorbed dose } \\ \text { RFETS } & \text { Rocky Flats Environmental Technology Site } \\ \text { SARP } & \text { Safety Analysis Report for a Package } \\ \text { SBR } & \text { styrene-butadiene rubber } \\ \text { SNL } & \text { Sandia National Laboratory } \\ \text { SRTC } & \text { Savannah River Technology Center } \\ \text { SS\&C } & \text { sand, slag, and crucible } \\ \text { TISAF } & \text { Thermal Insulating and Shock Absorbing Foam } \\ \text { WSMS } & \text { Westinghouse Safety Management Solutions }\end{array}$




\subsection{SUMMARY}

The purpose of this report is to document the technical basis for acceptance of the EPDM O-ring seals in the SAFKEG 3940A package proposed for storage of Pu-bearing material in the KAMS (K-Area Materials Storage) facility. Based upon limited available aging data, significant loss of compression set and stress-relaxation (90\% or more) of the O-ring is possible at the maximum service temperatures of the Inner Containment Vessel $\left(112^{\circ} \mathrm{C}\right)$ within $2-4$ years, assuming high oxygen availability. The maximum service temperature of the O-ring at the Outer Containment Vessel $\left(93^{\circ} \mathrm{C}\right)$ is less than at the ICV, and the O-ring compression set loss may not be as severe even at the high oxygen availability condition. Under limited oxygen and static environmental conditions, the O-ring seals may not exhibit this loss even after longer exposure periods.

Baseline characterization of the O-rings in both high and low oxygen concentrations is recommended in order to obtain compound-specific data at the relevant service temperatures. The characterization in combination with a surveillance program will help provide the data needed to assure long-term performance of O-ring seals under actual service conditions for the desired $10+$ years.

\subsection{BACKGROUND}

\subsection{SAFKEG 3940A Package Design}

Pu-bearing materials (metal, oxides, and impurities) placed in 3013 containers are to be shipped to SRS in Model 9975 packaging assemblies for interim storage at the K-Area Material Storage (KAMS) facility prior to final stabilization. An alternate package (SAFKEG 3940A) made by Croft Associates, Ltd. (est.1980) has been proposed for the same application. The 3940A package is one of a series of SAFKEG packages made by Croft for the packaging and transportation of radioactive materials.

The 3940A SARP (Safety Analysis Report for a Package) is in the process of being approved by the Los Alamos National Laboratory (design authority) [1]. The 3940A package is a general purpose container for the shipment of Type B radioactive material.. The 3940A package was designed for a contents heat limit of $40 \mathrm{~W}$, but the SARP is restricted to $20 \mathrm{~W}$.

The 3940A package (Figure 1) consists of a double-skin insulated stainless steel keg that is 760 $\mathrm{mm}$ (30 in.) long and $425 \mathrm{~mm}$ (16.7 in.) diameter [1]. The skin cavity is filled with a proprietary insulating phenolic resin foam (TISAF). Inside the keg is an insulating cork liner, sealed with a proprietary butylated sealant, that varies in thickness from $28 \mathrm{~mm}(1.1 \mathrm{in}$.) at the base of the keg to $75 \mathrm{~mm}(3 \mathrm{in}$.) at the top.

Inside the cork liner is a double containment configuration of resealable vessels, designs 3941 (outer containment vessel/OCV) and 3942 (inner containment vessel/ICV), Figure 2 [1]. Each vessel is made of stainless steel and sealed with two 3-mm (0.118") thick O-rings of appropriate size. The interspace between them allows for leak testing. The containment boundary for each 
vessel is the inner O-ring. The lid is held in position by a threaded retaining ring, with both let into the body of the container to reduce vulnerability of the closure. The nominal weight of the packaging (excluding contents) is $108 \mathrm{~kg}(238 \mathrm{lb}$ ), with a maximum contents weight of $20 \mathrm{~kg}$ (44 lb). The lid may be fitted with a padlock to prevent the unauthorized removal of contents.

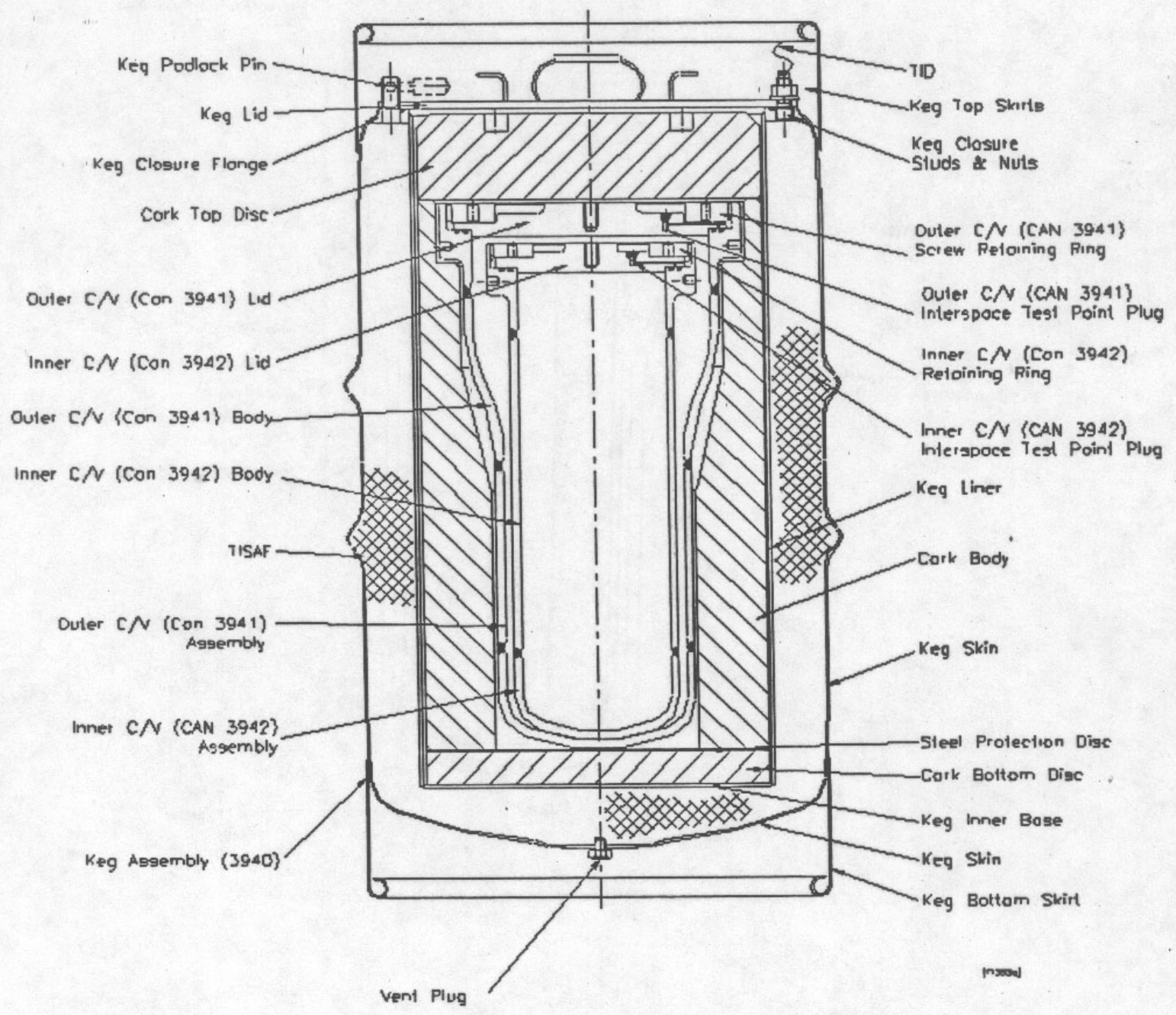

Figure 1. Overall Diagram of the SAFKEG 3940A Package Assembly [1]. 


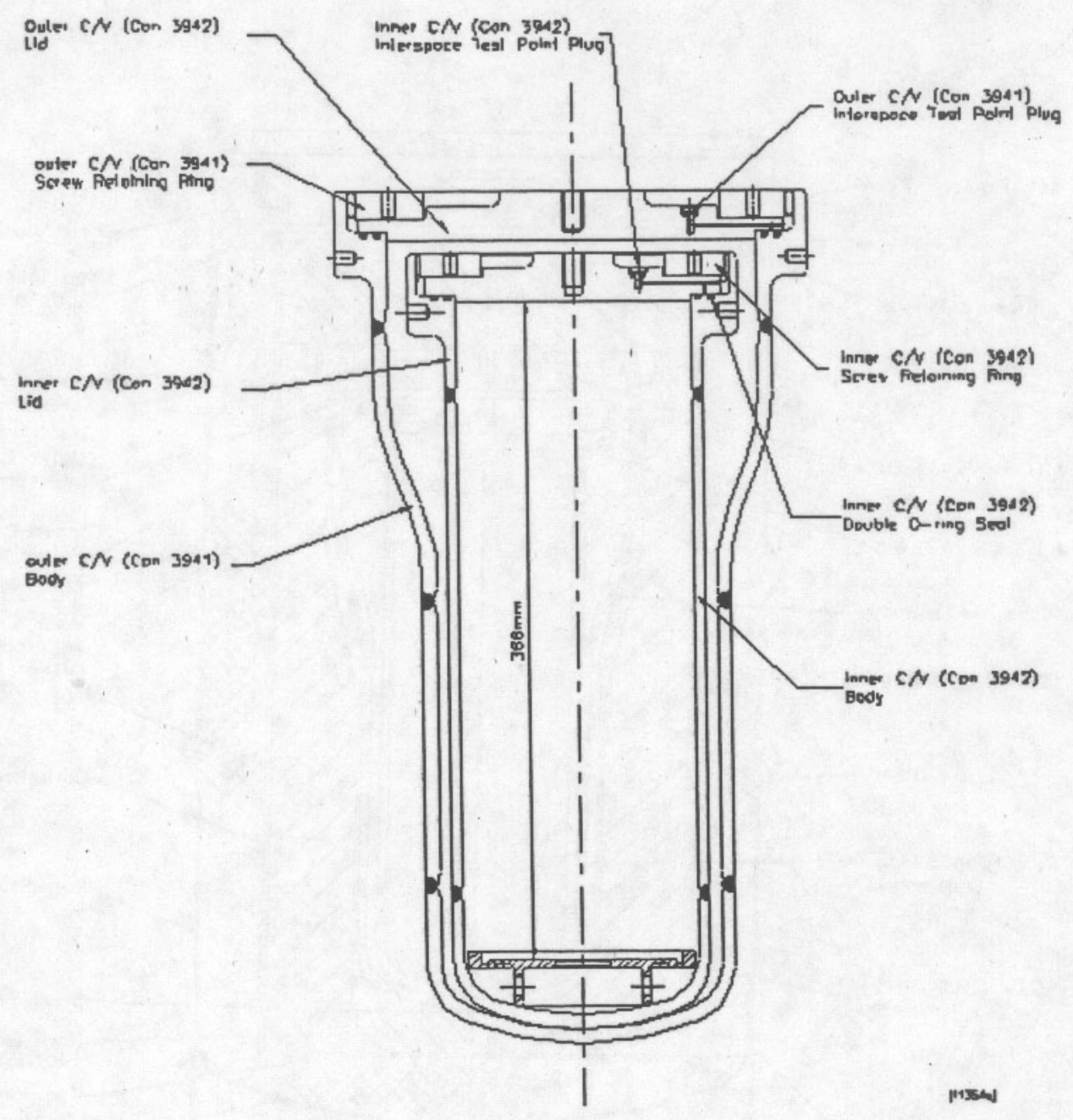

Figure 2. Inner and Outer Containment Vessel Design, SAFKEG 3940A Package [1]. 


\subsection{O-Ring Material Specification}

The SAFKEG containment vessel O-rings are specified as EPDM (ethylene-propylene diene monomer) per ASTM D2000, line call-out: M3 BA610 A14 B13 F17 [1]. ASTM D2000 is a broad specification for rubber products used in automotive applications [2]. The letter $\mathrm{M}$ indicates metric (SI) units, followed by the grade number (3) and type BA material, which generically includes ethylene-propylene, high-temperature SBR, and butyl rubber compounds. The three digits (610) are for hardness $(6=60 \pm 5$ Durometer Type A) and tensile strength $(10=$ $10 \mathrm{MPa}$ (1450 PSI) minimum). The remaining designations are for specific heat resistance (A14), compression set (B13), and low-temperature resistance (F17) requirements.

This differs from the 9975 package where only a particular compound is specified (Parker V0835-75 based on Viton ${ }^{\circledR}$ GLT) [3]. Therefore, O-rings from different manufacturers may be used in the SAFKEG as long as the ASTM requirements are met. Per Croft, the O-rings are currently supplied by the Rainier Rubber Company, Seattle, WA (compound\# R0629-60). The technical basis for the compound specification is unknown. Rainier would not disclose the formulation for proprietary reasons but did provide a recent QA material test report. Properties are summarized in Table 1 [4]. Per Croft, EPDM seals are now specified instead of Viton ${ }^{\circledR}$ due to superior low temperature performance. The properties of Parker V0835-75 are given elsewhere $[3,5]$

\subsection{Service Conditions}

For transportation, the two cases normally of concern are Normal Conditions of Transport (NCT) and Hypothetical Accident Conditions (HAC). The bounding design conditions for the SAFKEG 3940A and Model 9975 packages are given in Table 2 [1,3]. The maximum NCT temperatures for the inner and outer vessel seals are $113^{\circ} \mathrm{C}\left(235^{\circ} \mathrm{F}\right)$ and $99^{\circ} \mathrm{C}\left(210^{\circ} \mathrm{F}\right)$, based on an ambient temperature of $38^{\circ} \mathrm{C}\left(100^{\circ} \mathrm{F}\right)$ and solar heating [1].

For storage in the KAMS facility, the temperature range is $0-120^{\circ} \mathrm{F}$ with no direct solar heating. The maximum normal storage temperatures for the SAFKEG 3940A inner and outer vessel seals are $\sim 112^{\circ} \mathrm{C}\left(234^{\circ} \mathrm{F}\right)$ and $93^{\circ} \mathrm{C}\left(199^{\circ} \mathrm{F}\right)$, respectively [6]. Though these temperatures are much lower than the continuous use rating of the O-rings $\left(160^{\circ} \mathrm{C} / 320^{\circ} \mathrm{F}\right)$ specified in the SARP, such ratings are typically only based on $\leq 1000$ hours of exposure and vague property changes $[1,7]$. Note that the 9975 package seal temperatures are lower than those of the SAFKEG under equivalent conditions, even though higher-temperature Viton ${ }^{\circledR}$ seals are used.

The radiation dose rates for the SAFKEG O-rings are unknown but assumed similar to those previously calculated for the Model $9975 \mathrm{PCV}$ seals (2 $\mathrm{rad} / \mathrm{hr}$ for SS\&C residues) $[5,8,9]$. This rate gives a total absorbed dose of $1.75 \mathrm{E}+05 \mathrm{rad}$ over 10 years, far less than the level expected to produce measurable property changes. However, dose rates for the SAFKEG seals could vary due to differences in package materials and geometry. 
The maximum normal operating pressure (MNOP) for both SAFKEG vessels is 8 bar/116 psi (abs). The maximum normal and design pressures for the 9975 vessels are much higher. The leak rate criteria for both transportation and storage in KAMS is $<10^{-7}$ bar std He cc/sec.

Table 1. Nominal Properties of Rainier Rubber O-Ring Compound\# R0629-60 [4] (Material Specification: ASTM D2000: M3BA610 A14 B13 F17)

\begin{tabular}{|c|c|c|c|c|}
\hline Property & Test Method & Specification & Tolerance & Actual Value \\
\hline Hardness, points & ASTM D2240 & 60 & $+/-5$ & 59 \\
\hline Tensile Strength, PSI & ASTM D412 & 1450 & $\min$. & 2000 \\
\hline Elongation, \% & ASTM D412 & 350 & $\min$. & 510 \\
\hline Tear Resistance, PPI & ASTM D624 & report & $\min$. & 244 \\
\hline Shrinkage, $\%$ & $\mathrm{~N} / \mathrm{A}$ & report & N/A & -2.33 \\
\hline Specific Gravity & ASTM D297 & 1.09 & $+/-0.03$ & 1.09 \\
\hline Compression Set, \% (22 hrs at $\left.158^{\circ} \mathrm{F}\right)$ & ASTM D395 & 25 & $\max$. & 19.12 \\
\hline Oven Aging, $70 \mathrm{hrs}$ at $212^{\circ} \mathrm{F}$ & ASTM D573 & & & \\
\hline change in hardness, points & & $(-) 10$ & $\max$. & $64(+5)$ \\
\hline change in tensile, PSI & & $(-) 25$ & $\max$. & $1952(-2.6 \%)$ \\
\hline change in elongation, $\%$ & & $(-) 25$ & $\max$. & \\
\hline Low Temperature Brittleness: & ASTM D2137 & minutes at $-40^{\circ}$ & & Pass (nonbrittle) \\
\hline
\end{tabular}

Table 2. Comparison of Bounding Conditions for SAFKEG 3940A and Model 9975 Packages

\begin{tabular}{|c|c|c|c|}
\hline Package & SAFKEG 3940A & Model 9975 & References \\
\hline Bounding Design Condition & \multicolumn{2}{|c|}{ Bounding Design Condition Value } & \\
\hline Design Temperature, Minimum & $(-) 40^{\circ} \mathrm{F} /{ }^{\circ} \mathrm{C}$ & $(-) 40^{\circ} \mathrm{F} /{ }^{\circ} \mathrm{C}$ & 1,3 \\
\hline Design Temperature, Maximum (NCT) & $147^{\circ} \mathrm{C}\left(297^{\circ} \mathrm{F}\right)$ & $200^{\circ} \mathrm{C}\left(402^{\circ} \mathrm{F}\right)$ & 1,3 \\
\hline Design Temperature, Maximum (HAC) & $200^{\circ} \mathrm{C}\left(392^{\circ} \mathrm{F}\right)$ & $200^{\circ} \mathrm{C}\left(402^{\circ} \mathrm{F}\right)$ & 1,3 \\
\hline Design Pressure, Minimum & 0 bar abs ( 0 psia) & 0 bar abs (0 psia) & 1,3 \\
\hline Design Pressure, Maximum (external) & 2 bar abs (29 psia) & & 1 \\
\hline Maximum Normal Operating Pressure & & 365 psig (PCV)/166 psig (SCV) & 3 \\
\hline Design Pressure, Maximum (internal) & 8 bar abs (116 psia) & $900 \mathrm{psi}(\mathrm{PCV}) / 800 \mathrm{psi}(\mathrm{SCV})$ & 1,3 \\
\hline Seal Radiation Dose Rates & $2 \mathrm{rad} / \mathrm{hr}$ (TBD) & $2 \mathrm{rad} / \mathrm{hr}$ & 9 \\
\hline Seal Temperature in Storage $\left(@ 130^{\circ} \mathrm{F}\right)^{*}$ & ICV: $243^{\circ} \mathrm{F} \quad$ OCV: $208^{\circ} \mathrm{F}$ & PCV:202 ${ }^{\circ} \mathrm{F} \quad \mathrm{SCV}: 200^{\circ} \mathrm{F}$ & 6 \\
\hline
\end{tabular}

* The maximum temperature previously assumed for Viton seals in the $9975 \mathrm{PCV}$ was $300^{\circ} \mathrm{F}$, with $252^{\circ} \mathrm{F}$ (SCV) and $264^{\circ} \mathrm{F}(\mathrm{PCV})$ being the highest O-ring seal temperatures expected under NCT [3]. 


\subsection{LITERATURE REVIEW}

\subsection{EPDM Chemistry, Formulation, and General Properties}

EPDM (ethylene-propylene diene monomer) is a synthetic elastomer developed in the 1960s primarily for aerospace and automotive applications, particularly for resistance to phosphate ester-based hydraulic fluids [7,10]. EPDM and EPR (ethylene-propylene rubber) polymers are made by halting crystallization during ethylene-propylene copolymerization, thus stabilizing an elastomeric phase well below room temperature. EPR copolymers are amorphous and are completely saturated (no active sites), with chemical crosslinking only possible with peroxides. If a third monomer (a non-conjugated diene) is added during copolymerization, the resulting elastomer (EPDM) is unsaturated and can be vulcanized or crosslinked by either sulfur or peroxides, as well as high energy radiation. The chemical structure of EPR/EPDM polymers is shown in Figure 3.

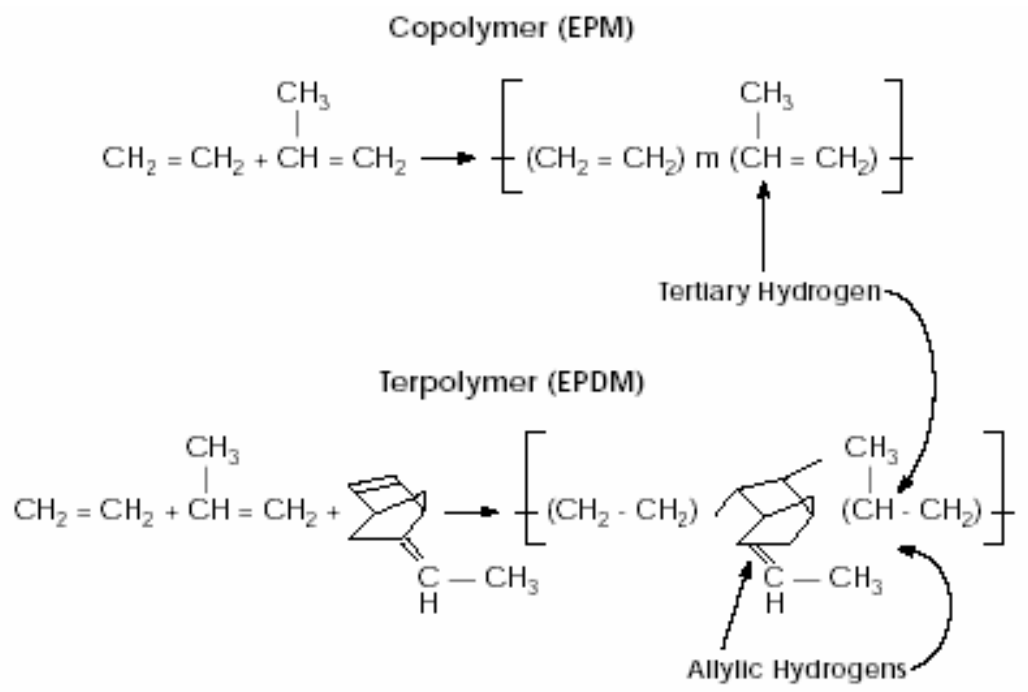

Figure 3. General chemical structure of EPR and EPDM polymers [11]

As with most elastomers, there are many grades of EPDM available, depending upon the properties required. The primary parameters include: the ethylene/propylene ratio, type and amount of termonomer, molecular weight (Mooney viscosity), and oil extension. For the most part, only three diene types are used: dicyclopentadiene (DCP), ethylidene norborene (ENB), and 1,4 hexadiene (HX) [10]. The molecular weights of most commercial grades of EPDM are between 200,000-300,000, and the Mooney viscosity (ML $1+4$ at $100^{\circ} \mathrm{C}$ ) is between $25-100$. Since in EPDM the unsaturation occurs only in side groups, the main backbone chain is fully saturated, leading to excellent resistance to oxygen, ozone, and chemicals. However, additives are required to maximize the aging resistance of EPDM but not for EPR. 
EPDM is non-polar and resistant to many chemicals including most salt solutions, alkaline solutions, steam, dilute acids, acetone, alcohol, and phosphate ester-based hydraulic fluids. EPDM is not resistant to aliphatic, aromatic, or chlorinated hydrocarbons or petroleum-based fluids and lubricants. It is also attacked by strong acids, particularly oxidizing types such as nitric [10].

EPDM is generally resistant to temperatures of up to $300^{\circ} \mathrm{F}$ in air, with slightly higher temperatures tolerable with specific compounding or in certain environments [7,10]. EPDM is not the most radiation-resistant elastomers, but it is usually the preferred elastomer for nuclear service due to its combined resistance to radiation, chemicals, aging, steam, compression set, heat, and other factors [12]. Peroxide-cured EPDMs are generally preferred over sulfur-cured types for superior heat aging and radiation-resistance properties [10,12 ].

For specific end-products such as O-rings, the compounder (e.g. Rainier, Parker Seals) procures the base raw polymer (ex. Nordel ${ }^{\circledR}$ 1440) and incorporates curing agents (peroxides, sulfur) and additives such as carbon black, antioxidants, UV/heat stabilizers, acid acceptors, and other processing aids. EPDM is most commonly sold under the Nordel ${ }^{\circledR}$ (DuPont-Dow Elastomers), Vistalon $^{\circledR}$ (ExxonMobil) or Royalene ${ }^{\circledR}$ (Uniroyal Chemical) tradenames, with many individual compounds available for specific needs. A typical EPDM formulation is shown in Table 2.

Table 2. A typical peroxide-cured EPDM formulation [10].

\begin{tabular}{ll} 
Constituent & phr (parts per hundred rubber) \\
\cline { 2 - 2 } Nordel $^{\circledR} 1440$ & 100 \\
Zinc oxide & 5 \\
N774 carbon black & 125 \\
Paraffin oil & 50 \\
Dicumyl peroxide (40\% active) & 8
\end{tabular}

EPDM vs. Viton ${ }^{\circledR}$

O-rings based on Viton ${ }^{\circledR}$ GLT fluoroelastomer (Parker V0835-75) are specified for the 9975 shipping package, primarily for both high and low temperature ratings $\left(-40\right.$ to $\left.400^{\circ} \mathrm{F}\right)$. Generically, Viton ${ }^{\circledR}$ fluoroelastomers (different types/grades) are more resistant to heat, flame and most chemicals than EPDM, particularly to acids, petroleum or hydrocarbon-based fluids, and solvents. EPDM is generally more resistant to amines, alkaline solutions and steam than Viton $^{\circledR}$, and is more resistant to radiation. The room temperature mechanical properties of both materials are comparable (compound-specific), with EPDM being more sensitive to elevated temperatures. EPDM typically exhibits better low-temperature performance, probably the basis for its use in the SAFKEG. Both materials are highly resistant to aging, ozone and oxidation, with Viton ${ }^{\circledR}$ being overall superior due to high fluorine content. 


\subsection{General Aging of Elastomers}

Aging of polymeric materials is a very complex subject. There are many variables that can influence the aging behavior of polymers, including: the base polymer type and specific formulation, heat, ionizing radiation (including ultraviolet), chemicals, ozone, and moisture. The presence and availability of oxygen is highly important, as oxidation is usually the dominant degradation process. There are also possible synergistic effects of multiple variables, radiation dose rate effects, diffusion-limited oxidation (DLO) effects, and many other aspects which further complicate such predictions.

Elastomers are particularly difficult to evaluate due to variation in compound formulation and processing. Compounds of the same polymer and similar physical properties can exhibit significant differences in aging depending upon cure times and temperatures, incorporation of additives such as antioxidants, etc. The performance characteristics or requirements also have to be considered, as some properties are more critical than others for a particular application and different properties are usually affected at different rates.

Continuous use temperatures often quoted by manufacturers are usually based on relatively short-term exposures (1000 hours or so) and nominal changes in properties [7]. While generally useful for designers and general material selection, such data is inadequate for predicting true service life, especially at elevated temperatures. Also, the criteria for such ratings may not be sensitive enough for some applications.

Historically, the thermal aging behavior of polymers and elastomers has been evaluated using an accelerated-aging methodology, in absence of real-time aging data. This approach usually involves exposing the material at several different temperatures higher than the desired service temperature (usually ambient) and measuring specific properties after some period of time. This methodology normally assumes Arrhenius behavior, represented by the relation below:

$$
\mathrm{k} \sim \exp \left(-\mathrm{E}_{\mathrm{a}} / \mathrm{RT}\right)+\mathrm{C}
$$

Where: $\mathrm{k}=$ rate of reaction, $\mathrm{E}_{\mathrm{a}}=$ activation energy, $\mathrm{R}=$ universal gas constant, $\mathrm{T}=$ absolute temperature, and $\mathrm{C}=$ constant

By assuming a constant activation energy over the extrapolation range, the time to reach a certain property value at the desired temperature can be predicted by using shift factors $\left(a_{t}=\exp \left(1 / T_{\text {ref }}\right.\right.$ $-1 / \mathrm{T})$ ) and superimposing data for the same property at elevated temperatures. This approach or principle is known as time-temperature superposition. Any property can be measured, with tensile strength, modulus, and elongation being the most common. However, these are not necessarily the most sensitive or the most relevant for all applications. 
As with any material, the service life of an elastomeric seal is truly the point at which the material fails to serve its intended function. In this case, specific leakage rate requirements must be met. Unfortunately, this requires complex leak testing of seals to be performed at elevated temperatures and is not a direct measurement of physical property changes.

The most important and relevant properties for elastomeric seals are generally considered to be compression set/recovery and compression stress-relaxation (CSR) or sealing force decay. Elongation-to-break is also a good indicator of degradation, but is not necessarily as sensitive or as relevant. High values of compression set (80-100\%) or low values of retained sealing force (F/Fo 0.10) are often used as "failure" points, or levels of degradation at which seal integrity is highly questionable. Elongation values such as $50 \%$ absolute or $10 \%$ of initial elongation are also often defined as points of "failure".

Obviously, service life is also dependent upon the pressure differential and the nature of the application. Low pressure seals and those not subject to dynamic conditions are more tolerant of material degradation and loss in sealing force. In fact, seals with $100 \%$ compression set or stress-relaxation can still be highly functional unless disturbed. The more stringent the criteria, the more sensitive to degradation the seal becomes.

Therefore, care must be taken in the definition of failure for elastomeric seals and the test methods employed to evaluate seal performance. Comparison of data obtained by different researchers on different compounds under different conditions using different test methods and failure criteria is of limited value.

\subsection{Thermal Aging of EPDM Elastomers}

A review of available data on the aging of EPDM elastomers was performed. As in the 9975 package and most cases of radioactive material (RAM) transport, the radiation levels expected for the SAFKEG seals are considered very low. In addition, most radiation-aging studies evaluate materials at much higher dose rates than encountered in actual service and for greater cumulative doses. Therefore, the focus of this report is primarily on thermal aging. It must be emphasized that this data is very limited, compound-specific, and does not necessarily address all relevant service conditions.

In summary, most studies involve the use of accelerated aging methodology to evaluate the performance of EPDM elastomers under ambient conditions, rather than focusing on aging behavior at elevated temperatures. However, data on short-term exposures at elevated temperatures for a few EPDM compounds was found and is believed to be quite relevant for the SAFKEG package application.

In a recent study [14], O-ring materials used in weapon systems were evaluated for thickness variability and compression set/recovery behavior after being compressed for one year at temperatures of 60,70 , and $80^{\circ} \mathrm{C}$. At these temperatures, EPDM compound Parker E692-75 exhibited an average compression set of $33 \%$ and $23 \%$ at 80 and $60^{\circ} \mathrm{C}$, respectively, compared to 
15 and $13 \%$ for a Viton ${ }^{\circledR}$ and 95 and $61 \%$ for a nitrile rubber compound. Unfortunately, higher temperatures and/or longer periods were not evaluated.

Other references [15-18] document an extensive amount of short-term testing performed over the years at Sandia National Laboratories in support of the Office of Civilian Radioactive Waste Management (OCRWM) and the DOE Office of Defense Programs to evaluate the performance of seals commonly used in radioactive material packages. These tests were performed at both high and low temperatures for several commonly specified O-ring compounds. No work relevant to aging was performed.

In these studies, several O-ring compounds were evaluated, including EPDM (Parker Seal) compounds E0740-75, E0893-80, E0540-80, as well as Parker V0835-75 used in the 9975 package. These compounds were leak tested at $380^{\circ} \mathrm{F}\left(193^{\circ} \mathrm{C}\right)$ for a 2 hour period with zero failures. Relatively low compression set values (9-13\%) were measured for the short exposures. Additional tests were performed at temperatures $30^{\circ} \mathrm{F}\left(17^{\circ} \mathrm{C}\right)$ higher than previous tests for a 3hour use period, again produced no failures.

Low temperature testing was also performed, with only the Viton ${ }^{\circledR}$ O-ring seals (V0835-75) producing failures at $-40^{\circ} \mathrm{C}$, the low temperature rating of the material. EPDM compounds consistently showed better low-temperature performance, maintaining leak-tight seals down to $50 / 60^{\circ} \mathrm{C}$. While useful for package design, such data is of little value for the prediction of O-ring lifetimes.

Perhaps most relevant to the SAFKEG package, one relatively recent study [19] investigated the lifetime prediction of EPDM O-rings for weapon components at ambient temperatures. EPDM O-rings were subjected to temperatures of $110^{\circ} \mathrm{C}$ to $155^{\circ} \mathrm{C}$, with Arrhenius behavior observed over the experimental range. The EPDM compound evaluated in this study (SR793B-80) is based on Nordel ${ }^{\circledR} 1440$ (DuPont-Dow Elastomers) and was custom-formulated for the AlliedSignal Kansas City Plant.

Conventional extrapolation of this data to $25^{\circ} \mathrm{C}$ yielded significantly long lifetimes $(55,000$ years). However, by using an ultrasensitive oxygen consumption analytical technique, activation energy values were found to change in the extrapolation region by $30 \%$ (116 to $82 \mathrm{~kJ} / \mathrm{mol})$. This improved methodology resulted in a predicted lifetime of 150 years at $52^{\circ} \mathrm{C}$ and 2000 years at $25^{\circ} \mathrm{C}$, reduced by a factor of 30 from conventional Arrhenius methodology.

While still very encouraging for aging at ambient conditions, this study indicates less encouraging long-term behavior of EPDM at elevated temperatures. Several properties of this compound were determined at $111^{\circ} \mathrm{C}, 125^{\circ} \mathrm{C}, 140^{\circ} \mathrm{C}$, and $155^{\circ} \mathrm{C}$ (Figures 3 and 4). As shown in Figure 3, the ultimate elongation dropped from an initial $180 \%$ to essentially zero after approximately 200 days $\left(6.56\right.$ months) at $125^{\circ} \mathrm{C}$, only slightly above the maximum SAFKEG inner vessel seal temperature $\left(112^{\circ} \mathrm{C}\right)$. At $111^{\circ} \mathrm{C}$, the elongation value was essentially zero after approximately 1000 days (2.74 years). In this study, the authors defined the mechanical "lifetime" of these seals as about 2 years at $111^{\circ} \mathrm{C}$ based on the amount of degradation observed. 
For the same EPDM material, the normalized force decay (F/Fo, decay in sealing force between the O-ring and mating surface) was determined at the same temperatures (Figure 4). A significant drop in sealing force was observed $(\mathrm{F} / \mathrm{Fo}<0.1)$ after 200 days at $125^{\circ} \mathrm{C}$ and after 580 days $(1.59$ years $)$ at $111^{\circ} \mathrm{C}$. From this data, the authors concluded that there is an "induction" period during which degradation is very limited, presumably due to the action of antioxidants. Other aspects of this study were documented in other references [20,21].

As with other studies, a major limitation of this data is that samples were oven-air aged in compression but with high oxygen availability. For lubricated O-rings sealed in a tight groove expanded at elevated temperature, the availability of oxygen for degradation is likely much lower. Degradation rates are likely very dependent upon the oxygen partial pressure, the diffusion rate of oxygen and the consumption rate.

It should also be noted that the EPDM compound used in this study has a much higher hardness (80A) than that specified for the SAFKEG package seals (60A). Variation in stress-relaxation behavior for the softer SAFKEG O-ring material is unknown and should be determined.

A subsequent study [22] extended the work from reference 19, applying laboratory test methods to EPDM O-rings of the same material that had been in service at ambient weapon conditions for $20+$ years. The mechanical "lifetime" of these O-rings was arbitrarily defined as the aging time required for the ultimate elongation of the material to reach $50 \%$ absolute (or about $10 \%$ of initial), which correlates closely with compression stress-relaxation properties.

As shown in Figure 5, it took 70 days to reach an absolute elongation value of $40 \%$ (10\% of initial) at $140^{\circ} \mathrm{C}$. Significant changes in density were also indicated at this point. Only density measurements were made on the older (23-year old) material due to limited quantity. With very little density change between aged and non-aged material, it was concluded that very little degradation has occurred in the surveillance material after 23 years at ambient weapon conditions.

Unfortunately, this data does not address long-term performance of EPDM O-rings at elevated temperatures. At 1000 hours (42 days), the time period typically quoted by manufacturers for "continuous" service temperature ratings, the same EPDM material (Figure 5) exhibits 180\% elongation or nearly $50 \%$ of initial. At this point, the material is still considered to be highly resilient and functional. However, after only 90 days, the elongation is practically zero, indicative of much less sealing capability under the tested conditions. 


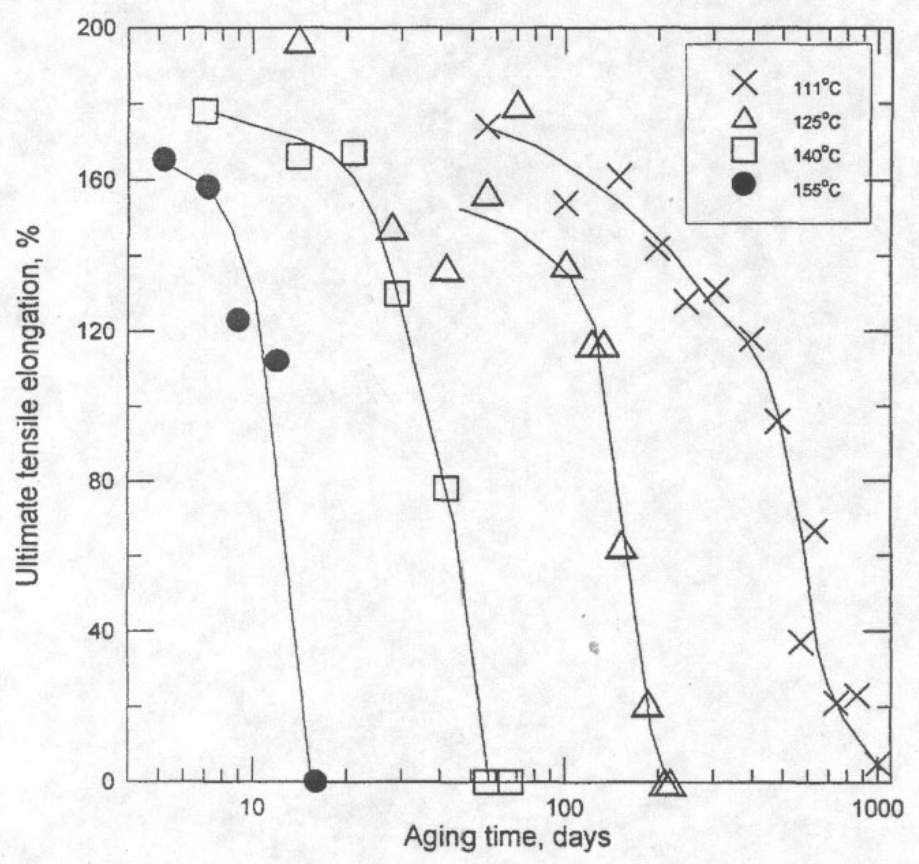

Figure 4. Ultimate tensile elongation data vs. aging time for EPDM [19]

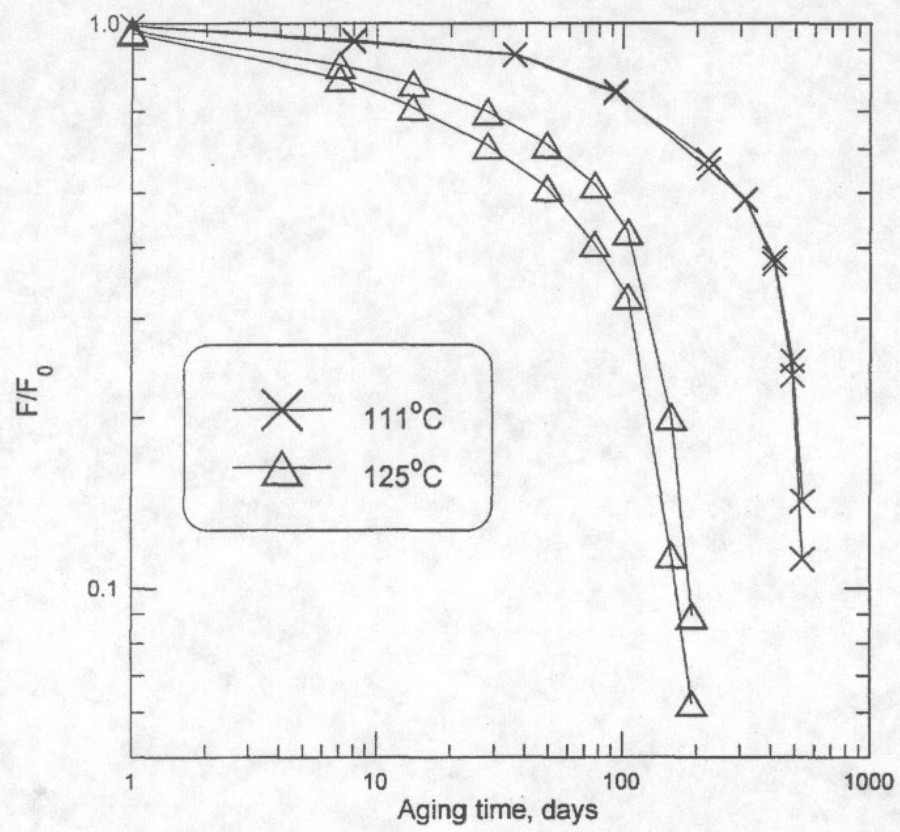

Figure 5. Normalized compression stress-relaxation force data vs. aging time [19] 
In another study [23], the stress-relaxation behavior of two different O-ring materials (EPDM and butyl rubber) used for weapon components was evaluated. Accelerated compression stress relaxation tests indicated that the EPDM compound was far superior to the butyl rubber and that the optimum postcure for the EPDM was $2-4$ hours at $182^{\circ} \mathrm{C}$ in vacuum. For a service life requirement of 20-25 years, stress relaxation tests were performed for a maximum of 616 days.

The EPDM compound evaluated in this study was designated SS384725, based on Nordel ${ }^{\circledR}$ 1440. Compression set values for this compound after 70 hours at $125^{\circ} \mathrm{C}(25 \%$ compression) ranged from $3.3 \%$ ( 2 hour vacuum postcure at $182^{\circ} \mathrm{C}$ ) to $10.7 \%$ with no postcure. Stress relaxation tests were performed at $70^{\circ} \mathrm{C}$ and $80^{\circ} \mathrm{C}$ for 3 and 6 months respectively. The developmental EPDM compound exhibited much better stress-relaxation characteristics (lower relaxation) than the butyl compound over the 616-day exposure period.

At $80^{\circ} \mathrm{C}$, the EPDM compound maintained a relatively high $\mathrm{F} / \mathrm{Fo}$ ratio of $\sim 0.65$ (initially 0.80 ) for the entire period (616 days). In comparison, the butyl compound ratio dropped from 0.55 to around 0.10 at $70^{\circ} \mathrm{C}$ after 616 days (indicating a significant loss in sealing force) and to 0.32 after only 93 days at $80^{\circ} \mathrm{C}$, Figure 6 .

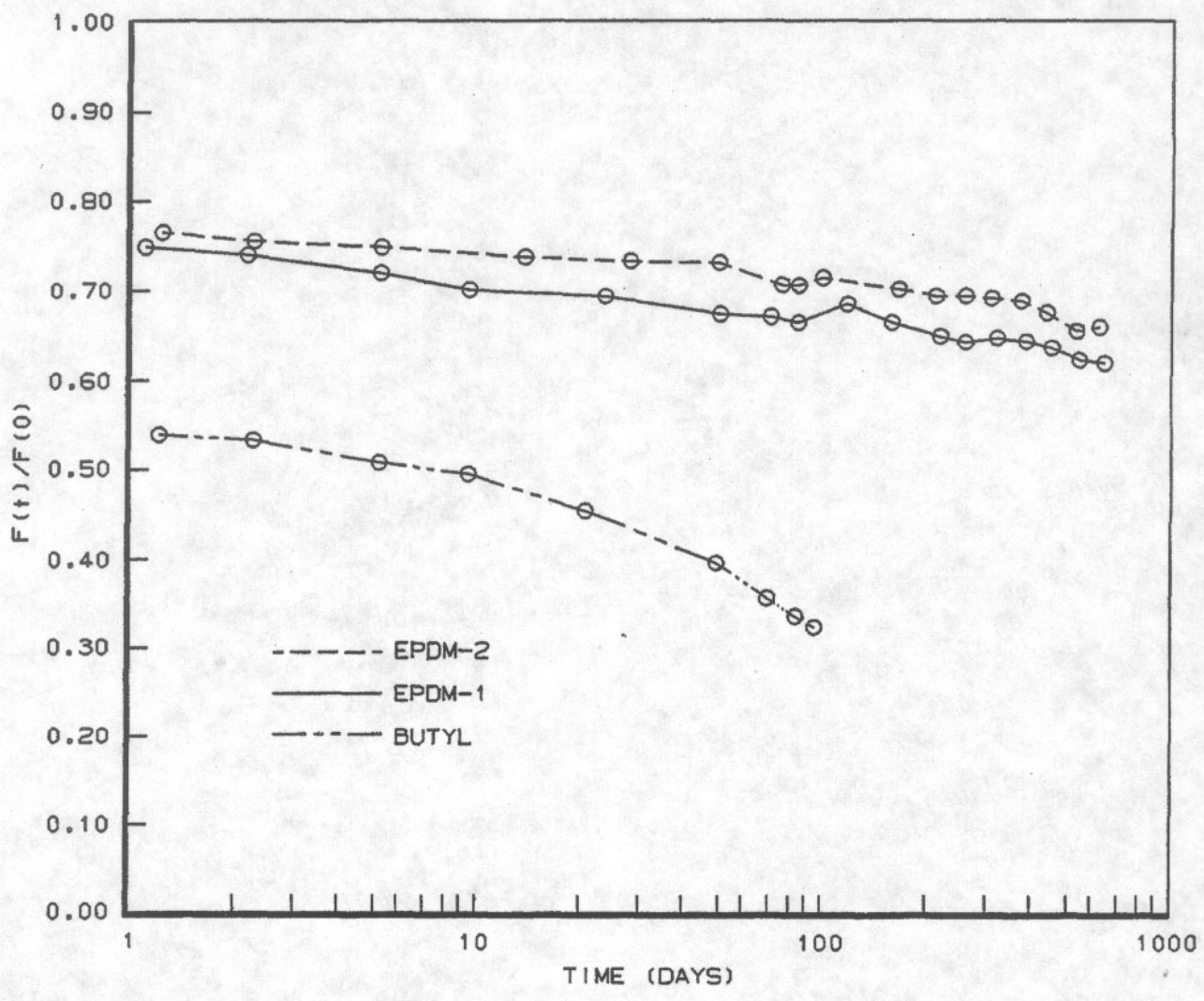

Figure 6. Stress Relaxation of Butyl and EPDM Elastomers at $80^{\circ} \mathrm{C}[24]$ 


\subsection{Summary of Literature Review}

EPDM elastomers are nominally rated by O-ring manufacturers for service temperatures of -70 to $300^{\circ} \mathrm{F}$ in air, with higher temperatures possible with compounding and in certain media. In most cases, the high-temperature continuous service ratings are usually generically based on adequate performance for 1000 hours in normal (usually fluid) applications. For most applications, such ratings are sufficient.

Unfortunately, the true service life of an elastomeric O-ring at elevated temperature is dependent upon many variables and can be defined in many ways. Elastomeric seals are known to function even when severely degraded, particularly under static conditions. Of course, the more critical the seal and the more stringent the criteria, the shorter service life becomes.

Based on the limited data reviewed, significant degradation and sealing force decay (compression stress-relaxation) of EPDM elastomers is possible at the maximum inner vessel seal temperature of $112^{\circ} \mathrm{C}$ (normal service) within 2-3 years, assuming high oxygen availability. The maximum outer vessel seal temperature is $93^{\circ} \mathrm{C}$. The time for significant sealing force decay would be expected to be extended beyond 2-3 years; however aging data at these conditions does not exist. There is likely a protective induction time (consumption of antioxidants) of approximately 280 days, beyond which the degradation rate will increase. For one EPDM compound, elongation was essentially zero after approximately 200 days at $125^{\circ} \mathrm{C}$ and after approximately 1000 days $(2.74$ years $)$ at $111^{\circ} \mathrm{C}$. Other studies indicate that EPDM compounds are highly stable after 2 years at $80^{\circ} \mathrm{C}$, but sealing force is essentially lost in the same time period at $125^{\circ} \mathrm{C}$.

This behavior is likely heavily influenced by several factors, particularly oxygen availability. As in the 9975 package, the benefit of limited oxygen exposure (lubricated O-ring tightly sealed in a groove within a double containment configuration) is believed to be significant but difficult to quantify. Degradation rates are known to be highly dependent upon oxygen availability, partial pressure, diffusion rates through the material, and the consumption rate. Most if not all of these factors are also dependent upon temperature and specific compounding. Therefore, additional investigation would be required to better evaluate these factors.

Assuming oxygen permeation from only one side of the O-rings and linear behavior between sealing force decay and oxygen diffusion/concentration factors, a service life of 4-6 years is estimated for the SAFKEG EPDM O-rings. Under static conditions, the seals are likely to maintain integrity well beyond this period, but this is unknown. Correlation between sealing force decay, compression stress-relaxation, and leak rate behavior at these temperatures for this or any other EPDM compound is also unknown. Additional testing and surveillance is therefore recommended. 


\subsection{SEAL PERFORMANCE}

There are several factors that will affect O-ring seal performance. These are briefly described here for discussion purposes.

\subsection{Seal Design}

Based on nominal O-ring sizes and SAFKEG O-ring groove dimensions, the percent compression or "squeeze" on the O-ring is approximately $30 \%$. This is slightly higher than but close to the value normally used $(25 \%)$ to determine the compression set of elastomers per ASTM test standards D395 [27] and D1414 [28]. Values of compression set are known to vary with \%compression, as well as with the temperature and time compressed. Higher values can overstress the material, inducing excessive compression set. Thermal expansion differential between the EPDM and stainless steel at temperature could also affect the compression.

\subsection{Permeability}

Gas or fluid leakage in elastomeric seals can occur for two reasons: bypass leakage (around the O-ring) or permeability (through the O-ring). The permeability of gas through an elastomer also depends upon many factors, including but not limited to: cross-link density, polymer type/structure, percent squeeze or compression, temperature, and gas molecular weight. As many such properties are directly dependent upon compounding, permeability is very compoundspecific. No permeability data specific to the Rainier compound was available. Generic data available for certain gases at particular temperatures for generic material types is provided in the Parker O-Ring Handbook for comparison [7].

Permeability of the O-ring may change with temperature and degradation but will not affect the release of vessel contents. Hydrogen or helium generated during radiolysis of organic materials or by decay of contents will likely permeate through the O-rings, possibly reducing pressure build-up within the container. Permeability characteristics of the SAFKEG O-rings at elevated temperature are unknown.

\subsection{Failure Criteria/Leak Testing}

For the 3940A SAFKEG package, the acceptance criteria for both transportation and storage in KAMS is a $1 \times 10^{-7} \mathrm{cc} / \mathrm{sec}$ helium leak rate with one atmosphere differential pressure across the seal boundary [1]. Helium is a very low molecular weight gas and permeates rapidly through elastomers, particularly at elevated temperature. Therefore, leak testing must be performed in a manner such that leakage is distinguished from permeation. As with permeability, gas leakage around an O-ring is dependent upon the pressure differential across the seal boundary. A leak rate of $1 \times 10^{-7} \mathrm{std} \mathrm{cc} / \mathrm{sec}$ at one atmosphere pressure differential will generally increase at higher pressures, as leak rate is generally proportional to the square of the pressure differential. The 
true failure criteria is the point at which the material fails to pass the acceptance criteria. This point may significantly differ from that predicted by other properties.

\subsection{Accident Conditions after Aging}

A significant limitation of package qualification for transport vs. storage is that the potential for O-ring failure (leakage, etc.) under accident or hypothetical condition is normally only evaluated for pristine O-rings subject to elevated temperatures for short periods. Although this approach shows that O-rings can usually maintain a seal well above their continuous service limits for at least some period of time, it does not adequately address O-ring behavior after significant aging.

This limitation is true for other package qualification/evaluations as well, including the Model 9975. One way to address this issue would be to subject aged (artificially-induced by heat/radiation or in-service aged) O-rings of the same or similar compound(s) to leak tests under accident conditions. While this approach still does not duplicate all true service conditions (different compressive stress, oxygen exposure during aging, etc.), it would better simulate postaging accident behavior.

\subsection{Baseline Characterization}

The evaluation presented in this report is based on data generated for different EPDM compounds under different conditions, with different lifetime criteria applied. Since the aging behavior of all elastomers, including EPDM, is highly compound-specific, baseline characterization of the particular SAFKEG O-ring compound (Rainier\# R0629-60) is proposed. As a minimum, sealing force decay behavior (compression set relaxation) as a function of temperature and oxygen availability should be performed on this particular compound. This property should be evaluated at several different temperatures in the $100-160^{\circ} \mathrm{C}$ range for comparison with data for other compounds. Such measurements should ideally be correlated with leak test performance if possible. 


\subsection{CONCLUSIONS AND RECOMMENDATIONS}

5.1 The data reviewed indicates that EPDM O-ring seals subject to oven aging in air exhibit significant degradation within 2-3 years. However, with limited oxygen access and minimal changes in environmental conditions, the O-ring seals will very likely maintain sealing capability for longer periods. Correlation with property degradation and leak behavior is unknown. Baseline characterization in combination with a surveillance program will help provide the data needed to assure long-term performance of O-ring seals under actual service conditions for the desired $10+$ years.

5.2 Radiation dose rates are expected to be low relative to material degradation. However, differences in package geometry, materials and storage configurations could lead to variation in dose rates. Dose rate calculations for the 3940A package seals are therefore recommended.

5.3 While seal integrity is expected to be maintained, only a surveillance program can validate such a conclusion and determine in-service effects. Since no aging data are available for the specific O-ring compound used, sealing force decay tests under both high and low oxygen availability conditions are also recommended. Correlation with leak rate behavior would be highly desirable.

5.4 The EPDM seals were presumably selected for the SAFKEG package in lieu of Vitonbased compounds for superior low-temperature performance to meet transport criteria $\left(-40^{\circ} \mathrm{F}\right)$. For storage in KAMS, this criteria does not apply. Although the EPDM seals can be effective in this application, Viton ${ }^{\circledR}$ compounds are expected to offer superior resistance to thermal aging at the maximum seal temperatures expected in KAMS.

5.5 Performance of the O-ring seals under accident conditions following significant aging degradation is unknown. This aspect could be evaluated in the short-term by monitoring leak performance of artificially-aged O-rings under accident conditions. This would be more complex than leak testing at room temperature due to increased permeation and other variables. The data from a surveillance program can also guide the prediction of performance of the Orings under accident conditions.

\subsection{QUALITY ASSURANCE}

The work in this report involved the compilation and evaluation of information from literature sources. Execution of this technical work and its documentation were performed in accordance with the requirements in the WSRC E7 Manual, procedure 3.60. Internal technical review of this report is governed by the WSRC E7 Manual, procedure 2.40. 


\subsection{REFERENCES}

1) LAUR-01-2081, Rev.1, Safety Analysis Report for a Package, SAFKEG 3940A (Draft)

2) ASTM D2000-01, Standard Classification System for Rubber Products in Automotive Applications.

3) Safety Analysis Report - Packages, 9965, 9968, 9972-9975 Packages (U), WSRC-SA-7, Revision 6, October 1998.

4) Rainier QA Test Report, Compound\#R0629-60, Batch\#112788A-001, May 2000.

5) WSRC-TR-98-00439, Performance Evaluation of O-Ring Seals in Model 9975 Packaging Assemblies (U), T. Eric Skidmore, December 1998

6) M-CLC-K-00660, Rev. 0, "Thermal Analysis of the SAFKEG Package for KAMS Project," N.K. Gupta, May 2003.

7) Parker O-Ring Handbook, ORD 5700, Parker Seals, O-Ring Division, 2001.

8) N-CLC-F-00141, Rev.0, "N-CLC-F-00141, Rev 0, "Shielding Analysis for Plutonium Fluoride Payload in 9975 Shipping Container," September 1998.

9) WSMS-CRT-98-0097, S. Nathan to E. Skidmore, December 18, 1998.

10) W. Hofmann, Rubber Technology Handbook, 1989. Hanser Publications.

11) Vistalon EPDM elastomers, ExxonMobil web site technical bulletin

12) D. Ramsdell, R. Barbarin, "Selecting Elastomer Seals for Nuclear Service”, Parker Seal Group, Technical Bulletin \# 23B, March 25, 1989.

13) SAND00-8259, "Experimental Evaluations of O-Ring Thickness Variability and LongTerm Compression Set and Compression Set Recovery"

14) SAND94-2207, "Performance Testing of Elastomeric Seal Materials under Low and High-Temperature Conditions: Final Report"

15) D. R. Bronowski, K. B. Sorenson, "Development of a Technique for the Leak Testing of Elastomeric Seal Materials at High Temperature", PATRAM'95 Proceedings, The $11^{\text {th }}$ International Conference on the Packaging and Transportation of Radioactive Materials, December 3-8, 1995, pp.1775-1782. 
16) D. R. Bronowski, P. E. McConnell, "Performance Characteristics of O-Ring Seals for Radioactive Material Packages When Subjected to Extreme Temperatures", PATRAM'95 Proceedings, The $11^{\text {th }}$ International Conference on the Packaging and Transportation of Radioactive Materials, December 3-8, 1995, pp. 1791-1798.

17) SAND98-1942, "New Methods for Predicting Lifetimes in Weapons. Part 1Ultrasensitive Oxygen Consumption Measurements to Predict the Lifetme of EPDM ORings"

18) SAND98-1726C) [ ], Limitations of The Arrhenius Methodology, October 1998 [ ]

19) SAND2000-0715, "New Methods for Predicting Lifetimes - Part 2: The Wear-Out Approach for Predicting the Remaining Lifetime of Materials"

20) SAND98-0854C, "New Method For Predicting Lifetime of Seals from Compression Stress Relaxation Experiments" (1998)

21) SAND97-2181C, "Evidence that Arrhenius High-Temperature Aging Behavior for an EPDM O-ring Does Not Extrapolate to Lower Temperatures".

22) KCP-613-5806, “Accelerated Aging of EPDM and Butyl Elastomers”, Federal Manufacturing \& Technologies, M.H. Wilson, 1996.

23) C. Decker, F. Mayo, H. Richardson, "Aging and Degradation of Polyolefins, III. Polyethylene and Ethylene-Propylene Copolymers, Journal of Polymer Science, Polymer Chemistry Edition, Vol. 11: 2879-2898, 1973.

24) J. C. Vicic, D. Cain, S. Roldan, L. Su, C.C. Chen, "Life Estimation of Elastomers Using Temperature-Stress Acceleration Techniques”, Materials Performance, June 1991.

25) ASTM Standard D395-89, "Standard Test Methods for Rubber Property - Compression Set”, 1995 Annual Book of ASTM Standards, Vol. 9.01.

\section{Acknowledgements}

The author acknowledges the timely assistance from the following individuals: Susan IssacsBright and Faye Lewis (SRTC Technical Library), Michael Heidt and Dan Ewing (Parker Seals), Steve Smolinske and Jim Sears (Rainer Rubber Company), Bob Vaughan (Croft Associates, Ltd.), Tim Stone (LANL), Charlie Jenkins (SRTC/MTS), Travis White and Steve Nathan (WSMS/radiological input), and Ken Gillen, Mat Celina, Roger Clough and others at the Sandia National Laboratory for their extensive work in the area of accelerated aging of polymers and informal consultation. 